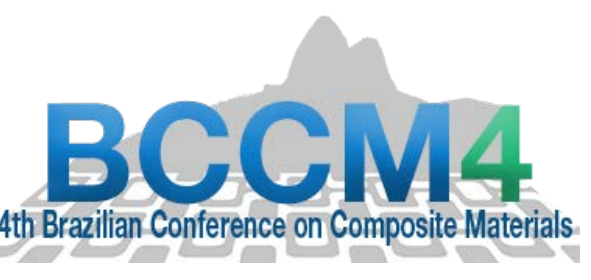

\title{
UTILIZATION OF CASTOR OIL TO PRODUCE AN AIR INCORPORATOR ADDITIVE FOR CONCRETES
}

\author{
Rodrigo M. S. Silva ${ }^{(1)}$, Amanda L. M. S. Melo ${ }^{(1)}$ and Filipe S. Duarte (1) \\ Federal Institute of Education, Science and Technology of Alagoas, Brazil
}

https://doi.org/10.21452/bccm4.2018.02.14

\begin{abstract}
The importance of developing efficient and sustainable alternatives to the high toxicity products in the civil construction market is one of the most relevant topics in Materials Science and Engineering worldwide. Within this reality are the additives for concrete and mortars, which despite being widely used products, are still produced without taking into consideration the environmental impacts that their substances cause to the environment. One type of additive that is increasingly in focus in the construction industry is the air incorporator to concretes additive type, used to produce the so-called "cellular concrete" that has the specific weight substantially reduced by the additive effect, generating great savings in works that use constructive systems with this type of concrete. The formulation used for the preparation of this type of additive by the industries present in the market is based on toxic materials that attack the environment, such as linear alkylbenzene and miscellaneous materials. Therefore, due to the high toxicity of these compositions, these products generate a high environmental impact when they come into contact with nature. From this reality, the present work proposes to elaborate a process for the development of a bioaddtive incorporating air based on castor oil (Ricinus communis L.), which was collected in the city of Arapiraca-AL, in northeastern Brazil. This process is described through the analysis of physical and chemical properties of the plant and experimental tests and dosages in order to analyze its quality in relation to the standards contained in the literature and thus contribute to the efficient, economical and sustainable evolution of civil construction.
\end{abstract}

\section{INTRODUCTION}

The chemical addition in the production of concrete and mortars modifies one or more properties of such mixtures. These chemical additives, being widely used in the construction industry, can be considered as the fourth component of concrete, in addition to water, cement and aggregates. It is possible to emphasize the importance of the additives and several additions, allowing significant changes in the mechanical properties and the durability of concretes [1].

The additive type IA (Air incorporators), has been increasingly used in Brazil and the world in the making of the so-called "cellular concrete". This additive aims to produce a microscopic bubble system that is stable and uniform, producing concretes with reduced 
specific gravity, with excellent thermal, acoustic behavior and considerable concrete savings in the work. These bubbles substantially improve the durability of concrete subjected to freezing and thawing stages, allowing greater workability in the fresh state [2].

Air-entraining additives produced by the construction industry are mainly composed of linear alkylbenzene sulfonate, such as: alkyl-arylsulphonated. Anionic surfactant is a surfactant, which is considered to be toxic. Some of the main environmental impacts of this substance are the decreases in the concentration of elements necessary for aquatic life, for example: dissolved oxygen, due to the reduction of water / air surface tension; decrease the permeability of light by keeping the particles present in suspension; increase of the concentration of xenobiotics and mainly the formation of foam and consequent inhibition of autodepuration of the water courses and dissipation of impurities.

The reasons for provoking the incorporation of air in the concrete are many, being the main ones: the increase of resistance to the cycles of freezing and thawing and the increase of the workability of the mixture and economy of building materials. These improvements are due to the air bubbles incorporated during the mixing process [3].

As a result of the absence of references on manufacturing methods for this type of additive, the objective of this work was to elaborate a process for the development of a bioaddress incorporating air based on the oil of the castor bean plant, collected in the city of Arapiraca-AL, northeast of Brazil. In this procedure, they are presented from the phases of collection of the vegetable and checks of quality of the raw material, until the preparation of fact of the additive.

\section{METHODOLOGY}

\subsection{Collection and reserve of the raw material.}

It is important to look that the castor plant, although to be a excelent adaptable plant, the clusters of the castor plant, where the seeds are, do not develop at the same time in the plant, since the flowering of the castor bean is called the botanical sympodial, where the appearance of the inflorescence takes place sequentially, between 20 and 35 days between

The collected fruits were left in the sun to dry and hatch, and then the seeds were stored in plastic bags until the time of their use. The storage should always be done in a dry and ventilated place. Figure 1 shows the dry, ready-to-use seeds, witch is the raw material for this process.

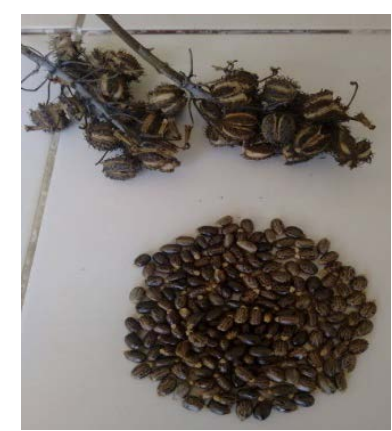

Figure 1: The raw material

\subsection{Analysis of the seed moisture}


Characterizing the properties of the materials of organic origin is an unpredictable factor, since there can be great variation in these properties influenced by several factors.

For this research, the analyses were performed in 4 samples of 2 grams weighed in a scale of 0.0001 precision, in order to compare its results and to draw a mean between the values.

\subsection{Extraction of oil from collected seeds.}

An important point about the used vegetable is the yield of its oil. The castor bean plant produces oil-rich seeds. In this work solvent extraction was used, using ethanol as the solvent for this process. In this extraction method, a liquid solvent is used to dissolve a solid or liquid substance from a solid mixture containing less soluble substances. In this process the separation of the phases occurs and then it is possible to separate the crude oil from the other substances of the seed through simple procedures of chemical separation of mixtures.

To extract the oil of the collected seeds, $40 \mathrm{~g}$ of seeds were ground in a mortar and homogenized with ethyl alcohol. The process of separating the oil and ethanol from the pie was done by filtration. The cake held in the filter was subjected to a simple filtration for 24 hours in order to obtain a more precise yield of the oil. Finally, to remove the alcohol from the oil, the mixture was heated to $80^{\circ} \mathrm{C}$. For the calculation of the oil yield, a relation was made between the mass of the dried seeds used and the mass of the oil obtained.

\subsection{Determination of the acid value of castor oil}

It is defined as the amount in (mg) of some base needed to neutralize the free acids present in one gram of oil or fat. [4] Indicate that the state of conservation of the oil is closely related to the origin and quality of the raw material.

The acidity index is a very important analysis to know the oil, since high acidity can disrupt the result of reactions that use it. For its determination, titration was made, in which titration was a solution of sodium hydroxide $(\mathrm{NaOH})$ and the indicator, phenolphthalein. The procedure consisted of weighing 7 grams of the oil in a $250 \mathrm{ml}$ Erlenmeyer flask, then adding $75 \mathrm{ml}$ of $95 \%$ ethanol and 3 drops of the $1 \%$ phenolphthalein indicator. For the calculation, the volume of $\mathrm{NaOH}$ spent in the titration per gram of the sample was used.

\subsection{Development of bubbles produce mechanism}

The next step of the process was the development of a bubbles produce mechanism. Soaps are produced from the oils by the saponification reactions, which is a neutralization reaction. The scientific name for the soap is sodium carboxylate, due to its forming reagents, which are esters and sodium hydroxide.

The stable and simple form of the compost was the purpose, then, for the production of the liquid detergent from the castor oil, the oil was mixed with ethyl alcohol, potassium hydroxide solution and water in a Becker.

\subsection{Elaboration of the additive}

The following phase was to improve the able of producing and retain bubbles. An acidbase reaction is a type of chemical reaction that occurs between an acid and a base and releases certain substrates. Several definitions exist regarding this type of reaction, which provide 
alternative concepts for the reaction mechanisms involved and their possible applications. The additive was produced from acid-base reactions in contact with the detergent produced, in order to retain the $\mathrm{CO} 2$ released by the reactions.

In this type of reaction in which the $\mathrm{CO}_{2}$ is released, when the $\mathrm{CO}_{2}$ is produced it causes a pressure and exits together with the solution, which results in a foam. This $\mathrm{CO}_{2}$ foam when in contact with natural detergent made with castor oil, becomes larger and more stable, that is, the viscosity of the detergent causes the $\mathrm{CO}_{2}$ released to be partially trapped.

\subsection{Analysis of performance of the additive}

To verify the performance of the air incorporator additive for concrete, 18 cylindrical specimens 10x20 cm were molded, of which 9 were filled with conventional concrete and 9 with the same concrete with the additive. The workability of the concrete were analyzed by the Slump Test, standardized in Brazil as cone trunk abatement test, according to [5]. The incorporation of air from the concretes were analyzed by the comparative weighing of the cylindical specimens of concrete molded with and without the additive.

\section{RESULTS AND DISCUSSIONS}

\subsection{Analysis of the seed moisture}

The percentage of moisture obtained in the samples is in agreement with the standards, close to the results found by [6]. See Figure 2 .

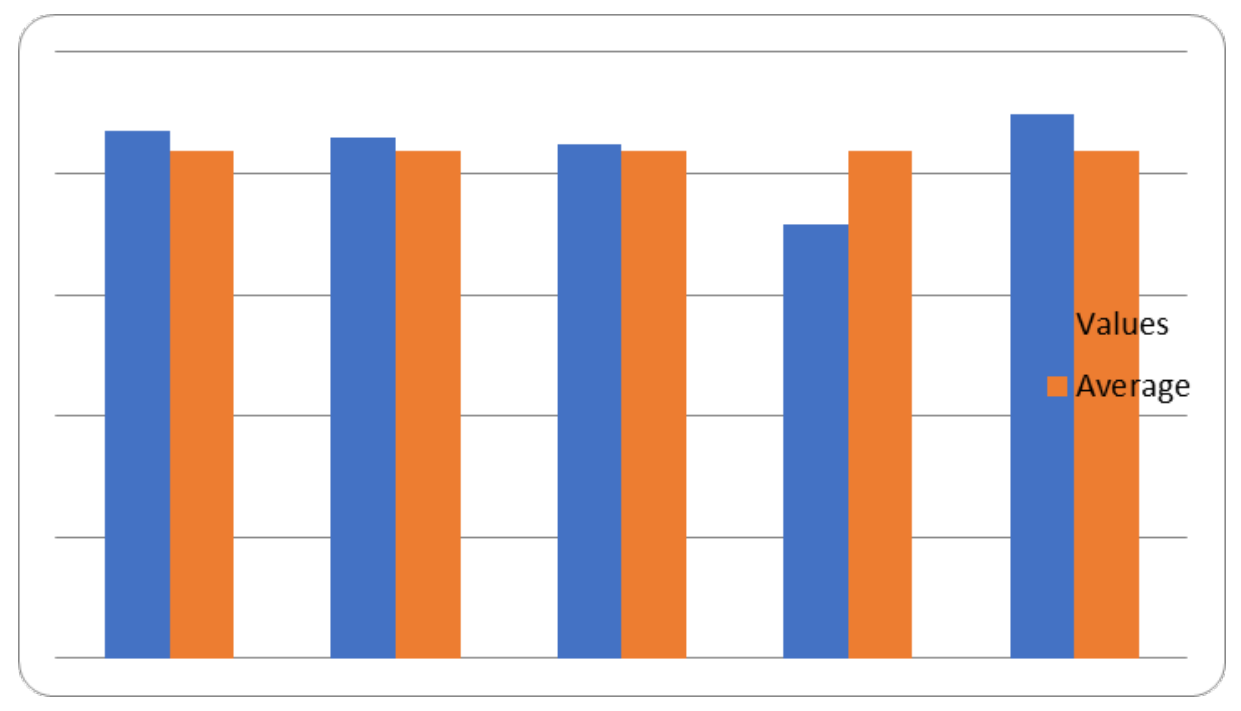

Figure 2: Seed moisture content.

\subsection{Extraction of oil from collected seeds}

The solvent extraction is a more modern procedure than pressing and is used to obtain higher yield than in other extraction processes. Processed seeds are immersed in the specific solvent and the separation is carried out chemically by distillation at special temperatures which causes only evaporation of the solvent, not the oil, followed by a filtration process to separate the oil from the solid part of the seed. 
After extraction, a ratio was calculated between the mass of the dried seeds used and the mass of the oil obtained. The yield was $39.7 \%$. The values were close to those found by [7], who reported values between $44 \%$. The procedures for extraction were quite satisfactory, as the result presented a value close to those cited. See Figure 3.

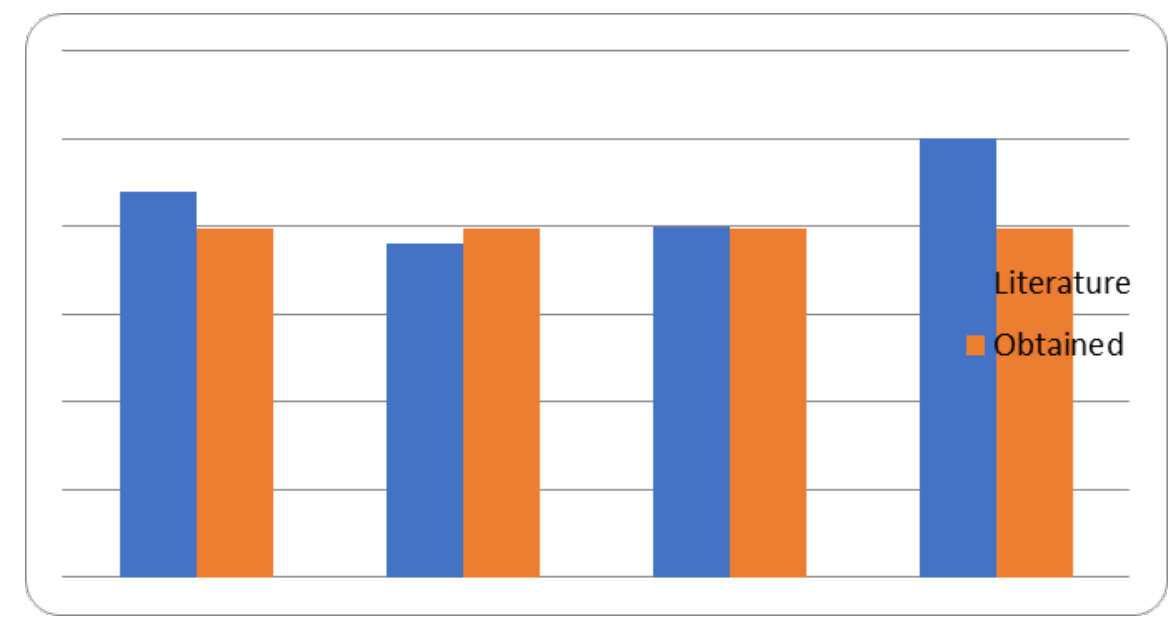

Figure 3: Average of the yeild of extraction.

\subsection{Determination of the acid value of castor oil}

If fatty acids form the oils and fats, a high amount of free fatty acids indicates that the product is in an advanced state of deterioration. A high acidity index indicates that the oil or fat is suffering breaks in its chain, releasing its main constituents.

The acid value is calculated by the volume equation of the titrate by the mass of the sample. The results of the test are presented in Table 1.

Table 1: Results of Acidity Index.

\begin{tabular}{cc}
\hline (mg) of KOH per gram of sample & 0,73432 \\
$(\%)$ of oleic acid & 0,3932 \\
\hline
\end{tabular}

\subsection{Development of bubbles produce mechanism}

The soaps are able to reduce the surface tension of the liquids that come in contact, reducing, in this way, the amount of interactions between the molecules that constitute it. A neutral liquid soap (detergent) was produced based on castor oil.

\subsection{Elaboration of the additive}

The produced additive was able to form a microbubble system with the $\mathrm{CO}_{2}$ released in the acid - base reactions retained inside, in a partially stable way. See Figure 4. 


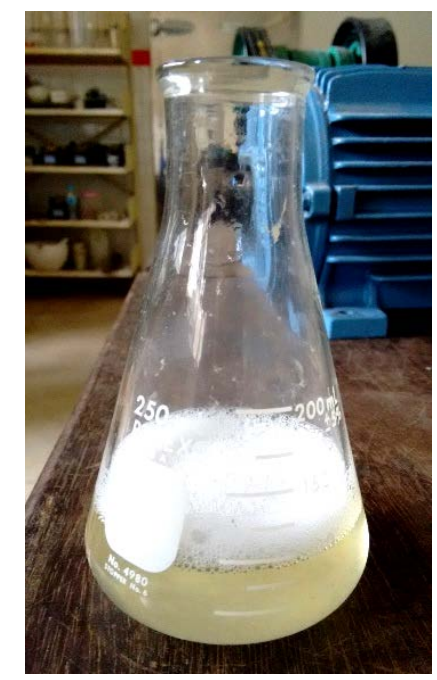

Figure 4 : Additive

\subsection{Analysis of performance of the addive}

According to [2], there are several factors that can interfere with the incorporated air content and, although the incorporated air content is not the only parameter that should be taken into account, it is the mainly parameter that need to be measured in the fresh state of concrete by the comparative weighing of the cylindical specimens molded with and without the additive.

The concrete made with the additive obtained an incorporated air content of $8.12 \%$ and a improvement of the workability of $20 \mathrm{~mm}$ in the Slump Test. See tables 2 and 3.

Table 2: Incorporation of air

\begin{tabular}{cccc}
\hline Dates & $\begin{array}{c}\text { Concrete weight } \\
\text { without additive }\end{array}$ & $\begin{array}{c}\text { Concrete weight } \\
\text { with additive }\end{array}$ & $\begin{array}{c}\text { Incorporation of } \\
\text { air }\end{array}$ \\
\hline 7 days & 3779 & 3444 & $8,86 \%$ \\
14 days & 3654 & 3321 & $9,11 \%$ \\
28 days & 3675 & 3441 & $6,37 \%$ \\
\hline Average & 3702,7 & 3402 & $8,12 \%$ \\
\hline
\end{tabular}

Table 3: Workability improvement

\begin{tabular}{cccc}
\hline Tests & $\begin{array}{c}\text { Meansure of the } \\
\text { concrete without } \\
\text { additve (mm) }\end{array}$ & $\begin{array}{c}\text { Meansure of the } \\
\text { concrete with } \\
\text { additive }(\mathrm{mm})\end{array}$ & $\begin{array}{c}\text { Improvement of } \\
\text { workability } \\
(\mathrm{mm})\end{array}$ \\
\hline A & 100 & 122 & 22 \\
B & 89 & 115 & 26
\end{tabular}




\begin{tabular}{cccc} 
C & 93 & 105 & 12 \\
\hline Average & 94 & 114,0 & 20,0 \\
\hline
\end{tabular}

\section{CONCLUSIONS}

Based on the tests carried out for the determination of the moisture content of castor bean seeds, it was possible to verify that the samples had the necessary quality for the extraction of the oil. The oil obtained in the laboratory extraction process was adapted to the acid index indexes described in the literature. With this, it was possible to elaborate a method to develop an air incorporator additive for concrete, using as base raw material the vegetable oil of the castor bean plant, thus offering to the construction industry a new path for the development of products as alternatives to those currently on the market. Another important point was that it was possible to observe a significant increase in the concrete workability through the Slump Test procedure, in which it was verified that there was a $20 \mathrm{~mm}$ increase in the concrete abatement that used the additive. The incorporated air index, acquired with this additive, was on average $8,12 \%$, which is quite satisfactory and meaning a great saving of materials.

\section{REFERENCES}

[1] Pereira, M.R., Study of the addition of expanded clay in the formulation of lightweight concretes. Dissertation of M.Sc., Federal University of Rio Grande do Norte, Natal, Brazil. 2008.

[2] Kosmatka, S. H ., Kerkhoff, B ., Paranaense, W. C. Design and control of concrete mixtures. 14th ed. Stokie: PCA. 2003.

[3] Dolch, W. L. Air-Entraining Admixtures. In: Ramachandran, V. S. (Ed.). Manual of Concrete Admixtures: Properties, Science and Technology. 2nd ed. New Jersey: Noyes Publications,. P. 518-557. 1996.

[4] Ribeiro, E. P ., Seravalli, E.A. G . Food chemistry. Instituto Mauá de Tecnologia, Editora Edgard Blücher LTDA, São Caetano do Sul - SP, p. 111-143 and p. 169-173. 2001.

[5] Brazilian Association of Technical Standards. NBR NM 67: Concrete - Determination of consistency by cone trunk abatement. Rio de Janeiro. 1998

[6] Souza L.A ., Tonetti O.A.O ., Davide A.C. Determination of water content in castor bean seeds (Ricinus Communis L.) By greenhouse methods and microwave oven. II Brazilian Congress of Oleaginous Plants, Oils, Fats and Biodiesel, Varginha-MG. 2005.

[7] Machado C.C., Garcia A.R., Silva E., Souza A.P. Technical-economic analysis of the use of castor oil (Ricinus communis, L.) and mineral oils as lubricants for the motorcycle cut set. Revista Árvore 1998, n. 22 (1), p.123-134. 1998. 